\title{
THE EFFECT OF ORAL LACTOSE ON FAECAL FLORA AND $p H$ IN INFANTILE GASTRO-ENTERITIS
}

\author{
BY \\ B. ZILBERG \\ From the Children's Hospital, Birmingham
}

(RECEIVED FOR PUBLICATION JULY 30, 1956)

The close association of certain specific serological types of Esch. coli with diarrhoea and vomiting in infancy is now generally accepted (Taylor and Charter, 1952). It is not yet known, however, why some infants, from whose faeces these organisms are isolated, develop more severe symptoms while others have a mild illness and some remain symptom free.

It has recently been suggested by Ross and Dawes (1954) that the growth of these organisms in the intestinal tract may be influenced by certain environmental factors. These workers showed that specific Esch. coli types do not multiply at low $p \mathrm{H}$ values. They claimed that the resistance of the breast-fed infant to gastro-enteritis might be due to the low intestinal $p \mathrm{H}$ and lactobacillary flora, which are found in the child receiving human milk. Ross and Dawes (1954) attempted to lower the $p \mathrm{H}$ of the stools of a series of artificially-fed infants by the addition of lactose to National dried milk formulae, but they could only obtain a temporary and partial effect. Their studies, however, were carried out on healthy infants receiving normal feeds: they did not investigate the effect of oral lactose in infants suffering from gastro-enteritis who were receiving clear fluids or dilute milk feeds.

It seemed possible that the severity of the illness might be directly related to the quantity of the specific Esch. coli in the intestinal tract. Quantitative assessment of the daily faecal excretion of these organisms presents many technical difficulties. It was considered, however, that a rough estimate of the quantitative excretion of these organisms might be obtained by an investigation of their constancy of excretion in the stools.

The purpose of the present study was to investigate the effect of various oral doses of lactose on the faecal $p \mathrm{H}$ and lactobacillary flora of babies suffering from gastro-enteritis. This study also afforded an opportunity of finding out if there was any relationship between the severity of the symptoms and the constancy of excretion of specific Esch. coli in the stools.

\section{Patients and Methods of Investigation}

The patients in the whole series comprised 32 infants with clinical signs of gastro-enteritis, who were studied in the Children's Hospital, Birmingham, during the period January-August, 1954.

The illness was classified as severe, moderate or mild, according to the following criteria: severe, requiring intravenous fluids; moderate, requiring 'clear fluids' by mouth or gastric drip; mild, requiring dilute milk feeds. Infants with parenteral infections were not excluded from the series and antibiotics were used in these cases.

The infants were allocated, on admission or on clinical evidence of cross-infection, alternately to the lactose group and to the control group. The last four infants were added to the lactose group in order to increase the number of cases in this group.

Lactose Group. The initial treatment was with clear fluids consisting of lactose in $\mathrm{N} / 5$ saline. The first two infants were given $5 \%$ lactose: as this dosage was well tolerated, but did not produce any alteration in the $p \mathbf{H}$ of the faeces, the next seven infants were given $10 \%$ lactose, and the last nine infants received $20 \%$ lactose.

When milk feeds were begun, lactose was added in place of sucrose; the percentage of lactose in these feeds then fell from the initial figures of $5 \%, 10 \%$ and $20 \%$, to $5 \%, 7 \cdot 5 \%$ and $11-12 \%$ respectively.

Control Group. The initial clear fluid in this group was $5 \%$ dextrimaltose in $N / 5$ saline, except when biochemical evidence of electrolyte imbalance indicated the use of other solutions. On beginning milk feeds sucrose was substituted for dextrimaltose, the sugar content of the feed then reaching $7 \cdot 5 \%$.

Investigations. Before the start of therapy a specimen of faeces for bacteriological examination was obtained from each child. Thereafter subsequent daily specimens were obtained when possible. The following investigations were carried out on each specimen:

pH. This was estimated by means of B.D.H. indicator papers. 
Intestinal Flora. An assessment was made in two ways: (1) A faecal smear was stained by Gram's method and the proportion of lactobacilli in the smear was assessed by direct microscopical examination.

(2) The faeces were investigated for specific Esch. coli types: $0.111,0.55,0.26,0.86,0.114,0.125,0.119$, O. 44, E.10732, E.6111 and E.2581. Each specimen was plated directly on MacConkey's medium and incubated for 18 to 24 hours at $37^{\circ} \mathrm{C}$. At least four colonies from each plate were tested by slide agglutination against antisera to the above types. Confirmation of positive slide agglutination was obtained by tube agglutination to titre with $O$ and $B$ sera.

\section{Results}

The Effect of Lactose on $p H$ of Faeces. The initial faecal $p \mathrm{H}$ in the lactose group ranged from 4.9 to 8.5 with a mean of $6 \cdot 4$ : in the control group the corresponding range was $5 \cdot 5$ to $8 \cdot 8$ with a mean of $7 \cdot 2$. Only one infant (in the lactose group), who was partially breast-fed on admission to hospital, had a faecal $p \mathrm{H}$ below $5 \cdot 0$.

From Table 1 it will be seen that only one of the

TABLE 1

EFFECT OF ORAL LACTOSE AND DEXTRIMALTOSE ON pH OF FAECES IN INFANTILE GASTRO-ENTERITIS

\begin{tabular}{|c|c|c|c|c|c|c|c|c|}
\hline & & \multirow{2}{*}{$\begin{array}{l}\text { Total } \\
\text { Cases }\end{array}$} & \multirow[b]{2}{*}{$4-4 \cdot 9$} & \multicolumn{5}{|c|}{ Lowest Faecal pH Attained } \\
\hline & & & & $5-5.9$ & $6-6.9$ & $7-7 \cdot 9$ & $8-8.9$ & $9-10$ \\
\hline $\begin{array}{r}\text { Lactose } \\
50^{\circ} \\
10^{\circ} \\
20^{\circ}\end{array}$ & $\because$ & $\begin{array}{l}2 \\
7 \\
9\end{array}$ & $\begin{array}{l}0 \\
1 \\
9\end{array}$ & $\begin{array}{l}2 \\
5 \\
0\end{array}$ & $\begin{array}{l}0 \\
1 \\
0\end{array}$ & $\begin{array}{l}\mathbf{0} \\
\mathbf{0} \\
\mathbf{0}\end{array}$ & $\begin{array}{l}\mathbf{0} \\
\mathbf{0} \\
\mathbf{0}\end{array}$ & $\begin{array}{l}0 \\
0 \\
0\end{array}$ \\
\hline $\begin{array}{r}\text { Dextrima } \\
5 \%\end{array}$ & & 14 & 3 & 5 & 3 & 2 & 1 & 0 \\
\hline
\end{tabular}

nine infants receiving an initial dose of $5 \%$ or $10 \%$ lactose attained a faecal $\mathrm{pH}$ below 5.0 . On the other hand, the faecal $p \mathrm{H}$ fell below 5.0 in all nine infants receiving $20 \%$ lactose: this group, however, included the infant whose initial faecal $p \mathrm{H}$ was below 5.0. The low $p \mathrm{H}$ values attained on $20 \%$ lactose did not persist for more than a few days, and the $p \mathrm{H}$ reverted to the original values while the infants were on the same dose of lactose. In the infant whose initial faecal $p \mathrm{H}$ was $4 \cdot 9$, the $p \mathrm{H}$ remained unchanged for two days on $20 \%$ lactose and then gradually rose to $7 \cdot 9$.

These findings would suggest that, in infants with gastro-enteritis, a high dosage of lactose may produce a temporary reduction in faecal $p \mathrm{H}$.

The Effect of Lactose on Faecal Lactobacilli. On admission, only two infants had more than $25 \%$ lactobacilli in the faecal smears.
From Table 2 it will be seen that lactose in a dosage of $5 \%$ or $10 \%$ had no greater effect than $5 \%$ dextrimaltose in increasing the proportion of lactobacilli. However, in all nine infants receiving $20 \%$ lactose the proportion of lactobacilli rose above $50 \%$ : of the two children who attained over $75 \%$ faecal lactobacilli, the one receiving lactose required five days for this effect compared with 18 days for the child receiving dextrimaltose. Again, this increase in faecal lactobacilli lasted only a few days.

It would thus appear that lactose in high dosage can produce a temporary increase in faecal lactobacilli in children with gastro-enteritis.

TABLE 2

EFFECT OF LACTOSE ON FAECAL LACTOBACILLI

\begin{tabular}{|c|c|c|c|c|c|}
\hline & \multirow{2}{*}{$\begin{array}{l}\text { Total } \\
\text { Cases }\end{array}$} & \multicolumn{4}{|c|}{$\begin{array}{l}\text { Greatest Proportion of } \\
\text { Lactobacilli Attained }\end{array}$} \\
\hline & & $=$ & - & -- & $-\cdots$ \\
\hline $\begin{array}{r}\text { Lactose } \\
5^{\circ} \\
10^{\circ} \\
20^{\circ}\end{array}$ & $\begin{array}{l}2 \\
7 \\
9\end{array}$ & 2 & $\frac{1}{2}$ & $\begin{array}{l}1 \\
3 \\
8\end{array}$ & 1 \\
\hline Dextrimaltose & 14 & 2 & 4 & 7 & 1 \\
\hline
\end{tabular}

Effect of Lactose on Duration of Excretion of Esch. coli Types. Specific Esch. coli types were isolated from the faeces of 19 of the 32 children: type 0.111 from 16 ; type 0.55 from one; type 0.125 from one; type 0.26 from one.

In the lactose group, specific Esch. coli types were isolated from the stools of 10 of the 18 infants: eight of these 10 infants were still excreting the organism on discharge from hospital, at periods ranging from six to 19 days after beginning lactose.

In the dextrimaltose group, Esch. coli types were isolated from the stools of nine of the 14 infants: six of these nine infants were still excreting the organism on discharge, at periods varying from four to 36 days after commencing dextrimaltose.

These results indicate that lactose, as used in this trial, did not appear to exert a significant suppressive effect on the excretion of specific Esch. coli types.

Severity of Symptoms and Constancy of Excretion of Specific Esch. coli Types. For the purpose of this study a 'constant excretor' was defined as an infant from whom no stool culture negative for the infecting Esch. coli was obtained during the whole period of excretion of that type in his stools. An 'inconstant excretor' was an infant from whom one to three successive negative cultures were obtained during 


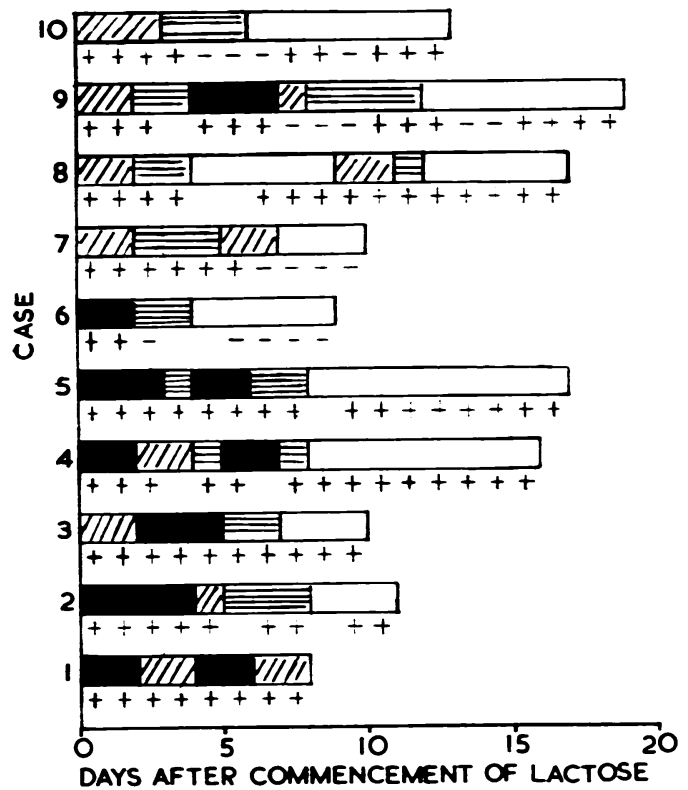

Severe illness $\quad+$ Esch. coli type isolated
Moderate illness $\quad-$ No Esch.coli type
isolated
Wild illness
Clinically well

FiG. 1.-Severity of illness and excretion of specific Esch. coli types in the lactose group.

the period of excretion of that organism: a positive culture obtained after more than three negatives was considered a re-infection.

Correlation of the severity of the illness with the excretion of specific Esch. coli types is depicted for the lactose and dextrimaltose groups in Figs. 1 and 2 respectively. In the lactose group, Cases 1-8 were constant excretors and Cases 9 and 10 inconstant excretors. In the dextrimaltose group, Cases 1-7 were constant and Cases 8 and 9 inconstant excretors. It will be seen that severe illness was always associated with constant excretion of the organism: on the other hand constant excretion of a specific type was occasionally obtained in infants who were clinically well. Both moderate and mild illnesses were sometimes associated with constant excretion and sometimes with inconstant excretion.

These findings might suggest that the severity of the illness bears some relationship to the quantity of specific Esch. coli excreted.

\section{Discussion}

The influence of diet on the intestinal flora and intestinal $p \mathrm{H}$ has been studied intensively by various investigators. It has been shown that a diet rich in carbohydrate produces a predominantly Grampositive 'aciduric' intestinal flora, whereas a highprotein diet results in a predominantly Gramnegative flora (Herter and Kendall, 1908, 1910: Hudson and Parr, 1924). The importance of lactose in producing this aciduric flora was stressed by Escherich (1886). Since then, many workers have investigated this effect. Thus, Hull and Rettger (1917) showed that a diet rich in lactose had a marked influence on the intestinal flora of man. Gerstley (1930) claimed that the addition of $12 \%$ lactose to the feeds of infants receiving cow's milk resulted in stools clinically and chemically similar to those obtained from breast-fed babies. On the other hand, Sisson (1917) could not confirm Gerstley's findings. The relationship of a low $p H$ with an aciduric flora was demonstrated by Cannon and McNease (1923). Subsequently, Cruickshank (1925) demonstrated in experiments in vitro that Esch. coli failed to grow in a medium whose $p \mathrm{H}$ was lower than $5 \cdot 0$.

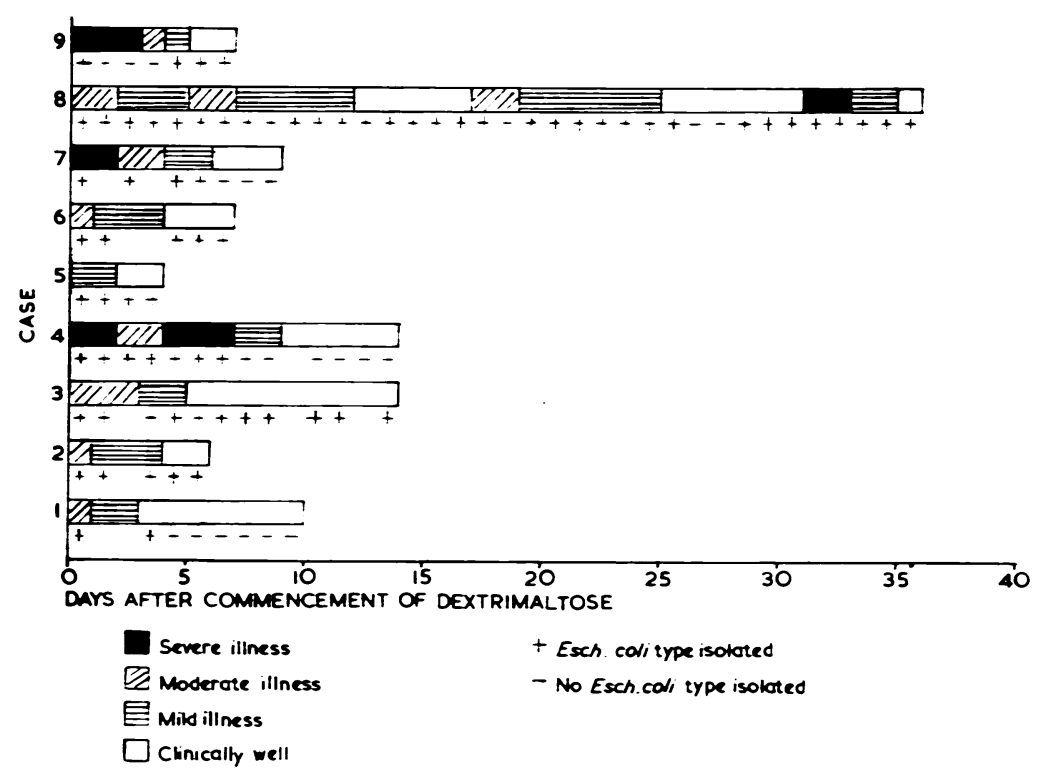

Fig. 2.-Severity of illness and excretion of spesific E.ch. coll types in the dextrimaltose group. 
The present study has shown that, in children suffering from gastro-enteritis who are receiving clear fluids or dilute milk feeds, the administration of oral lactose did not reduce the faecal $p \mathrm{H}$ below 5.0 until the lactose was given in a very high dosage $120 \%$ of the formula). Even with this high dosage the reduction in faecal $p \mathrm{H}$ was only temporary, and the $p \mathrm{H}$ rose again after a few days on this dosage. Coincident with the fall in $p \mathrm{H}$, the proportion of faecal lactobacilli increased, but never attained the predominance found in the stool of the breast-fed infant. These findings with oral lactose in children with gastro-enteritis are similar to those obtained by Ross and Dawes (1954) in healthy, artificially-fed infants.

It is evident from our investigations that the temporary reduction in faecal $p \mathrm{H}$, achieved by high dosage with lactose, was not sufficient to eliminate specific Esch. coli types. In order to find out if the temporary reduction in faecal $p \mathrm{H}$ achieved by lactose did exert any suppressive effect in vivo on the growth of these organisms it would be necessary to carry out serial quantitative estimations of the excretion of the specific type. This was not done in the present study. However, our finding that a severe illness was always associated with constant excretion of the organism might suggest that the quantity of a specific Esch. coli type excreted in the faeces bears some relationship to the severity of the disease.

György (1953) has shown that human milk contains a factor which is necessary for the growth of a strain of lactobacillus bifidus, and that this factor contains glucosamine, fucose and galactose. Springer, Rose and György (1954) studied the distribution of this 'bifidus factor' in human and animal secretions and showed that hog gastric mucin contained an appreciable quantity. As gastric mucin seemed suitable material to feed to infants, we added gastric mucin to the feeds of two infants who were not suffering from any intestinal disorder. It was given in a dosage of $3 \%$ for a period of seven days. No reduction in faecal $p H$ or increase in the proportion of faecal lactobacilli resulted in either of these infants. To achieve these effects it might be necessary to try several preparations containing the 'bifidus factor', in various dosages, over various periods of time. Again, it is possible that several interrelated factors are necessary for the production of the aciduric intestinal flora of the breast-fed infant.

\section{Summary}

In a series of infants with gastro-enteritis a high dosage of lactose $(20 \%$ of the feed) was required to lower the $p \mathrm{H}$ of the faeces below $5 \cdot 0$, and to produce a significant increase in faecal lactobacilli. These effects, however, were only temporary.

Lactose appeared to produce no suppressive effect on the excretion of specific Esch. coli.

A severe illness was always associated with constant excretion of the specific Esch. coli.

I wish to thank Professor J. M. Smellie for his interest and advice and for permission to publish this paper. I am grateful to Dr. K. B. Rogers for the bacteriological studies and to Dr. C. Ross for her constant help.

\section{REFERENCES}

Cannon, P. R. and McNease, B. W. (1923). J. infect. Dis., 175. 32, Cruickshank, R. (1925). J. Hyg. (Camb.), 24, 241.

Escherich, T. (1886). Die Darmbakterien des Säuglings. Stuttgart Gerstley, J. R. (1930). Amer. J. Dis. Child., 40, 27.

Gyōrgy, P. (1953). Pediatrics, 11, 98.

Herter, C. A. and Kendall, A. I. (1908). J. biol. Chem., 5, 293. , (1910). Ibid., 7, 203.

Hudson, N. P. and Parr, L. W. (1924). J. infect. Dis., 34, 621.

Hull, T. G. and Rettger, L. (1917). J. Bact., 2, 47.

Ross, C. A. C. and Dawes, E. A. (1954). Lancet, 1, 994

Sisson, W. R. (1917). Amer. J. Dis. Child., 13, 117.

Springer, G. F., Rose, C. S. and Gyōrgy, P. (1954). J. Lab. clin. Med. 43, 532.

Taylor, J. and Charter, R. E. (1952). J. Path. Bact., 64, 715. 